Universidad

辛: de Alcalá

BIBLIOTECA

Document downloaded from the institutional repository of the University of Alcala: http://dspace.uah.es/dspace/

This is a postprint version of the following published document:

Benayas, J.M.R.M. et al., 2010. A multiinstitutional spanish master's program in ecosystem restoration: Vision and four-year experience. Ecological Restoration, 28(2), pp.188-192.

Available at https://doi.org/10.3368/er.28.2.188

(C) 2010 Ecological Restoration

(Article begins on next page)
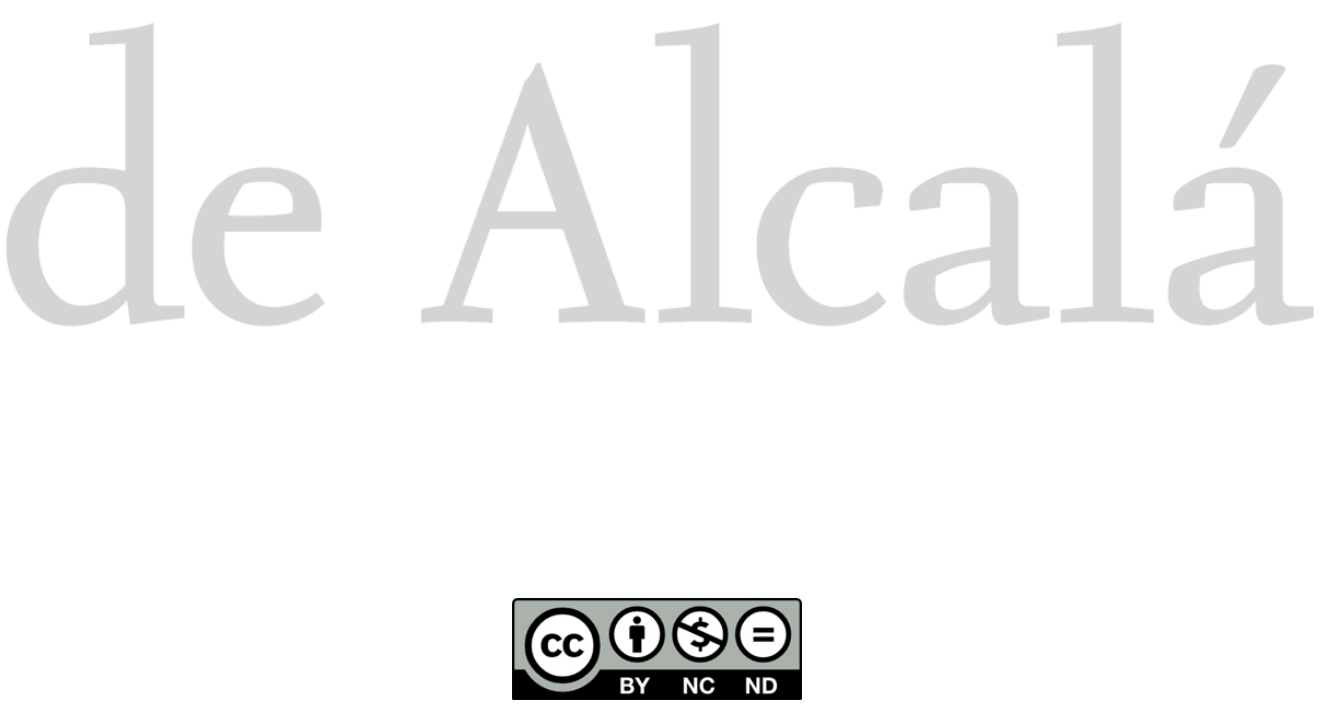

This work is licensed under a

Creative Commons Attribution-NonCommercial-NoDerivatives

4.0 International License. 


\title{
A Multiinstitutional Spanish Master's Program in Ecosystem Restoration: Vision and Four-Year Experience
}

José M. Rey Benayas, Adrián Escudero, José F. Martín Duque, José M. Nicolau, Pedro Villar-Salvador, Diego García de Jalón and Luis Balaguer

\begin{abstract}
Since 2006, an innovative, multiinstitutional Spanish Master in Ecosystem Restoration (MER) is jointly offered by four major public universities in Madrid. In view of the high student demand - about 900 applications this academic year for only 30 places, a remarkable $75 \%$ rate of professional poststudy employment in a period of economic crisis, and the high number $(>40)$ of prestigious organizations involved in the program, we consider the MER program, although still young, to be very promising for the long term. We explain the process to create the MER and achieve the results obtained thus far. We describe its organization, report its vital statistics in terms of students, and identify some strengths and weaknesses observed to date. The MER program has evolved as a network of knowledge and experience that links universities, lecturers, researchers, students, private and public companies, NGOs, and administration centers. Our aim is to help other groups that may want to launch similar graduate-level ecological restoration degree programs.
\end{abstract}

Keywords: active teaching and learning, European higher education, networking, professional training, Spain

The Spanish Master in Ecosystem Restoration, offered by four major public universities in the Madrid metropolitan area, was initiated in September 2003 by five senior lecturers with active research programs in restoration ecology. We were motivated by the obvious "boom" in scientific, legislative, media, and technical aspects of this field, as well as the growing social demand, the foreseeable employment demand, and the possibility of filling a noticeable gap in advanced teaching on this subject in Spanish, at both the national and international levels. It took three years to get started, and six years later, as the fourth cohort of students gets started, we consider the Spanish Master in Ecosystem Restoration (MER, www2.uah.es/master_rest_eco/) to be a success. Here, we explain the process that led to 
creating the MER, some keys to the results obtained, and the way the studies are organized. We also report on some vital statistics and identify some strengths and weaknesses. Our goal is to help other groups that may want to launch similar postgraduate study programs.

\section{Building the MER program}

The five founding lecturers, from four different universities, met together a number of times with the aim of creating a network that would follow the keys to successful team performance (Guimerà et al. 2005). These are 1) an adequate number of team members to launch an initiative; 2) previous collaborative experience (four of these five lecturers were members of the existing Madrid-based research network on ecological restoration named Remedinal; www.remedinal.org); and 3) collaborators with complementary expertise in order to enjoy synergistic effects. After brainstorming for two years, with additional consultations with university administrators and other researchers, we identified what we thought was an appropriate organization for this master of science (MSc) program, defined a core curriculum, located outstanding researchers in ecological restoration and related disciplines, and identified key institutions and organizations to approach as potential allies.

Our next step was to invite major lecturers to join the program. Fourteen people were identified and invited. Altogether, the team leaders and the invited lecturers represented six disciplines, namely, ecology, forest science, geology, soil science, geography, and economics. In the second year, one university declined to participate and we lost one faculty member. This lecturer was soon replaced by others with similar expertise, and since then the faculty has changed little. Five new lecturers have recently been incorporated to teach a subject introduced in the fourth year (more details below).

The implementation of the MER was facilitated by the fact that in Madrid the number of university departments, research labs, and people teaching and working in ecology is unusually high. It was easy as well to incorporate economists and a variety of engineers (for example, of forestry and hydrology). Additional keys were the support of the graduate schools at the four universities and the stubborn perseverance of team leaders under unfavorable administrative circumstances, which were mostly related to changes in official rules and excessive paperwork. The division of responsibilities among members of the program leadership was also critical. These responsibilities have included coordination of lecturers at each participating university, student selection and admission, coordination of enrolled students, practicum coordination, agreements with institutions involved in the program, coordination of subjects with more than one lecturer, and financial management. 
Not surprisingly, one of the most complex problems arose from the need to coordinate four public institutions whose staff were not in the habit of offering studies in an interuniversity context.

The MER is funded by the four participating universities and Remedinal. Tuition fees, defined by the Madrid Autonomous Government every year, were $€ 31.32$ or USD 46.98/credit ( $€ 1879.2$ or USD 2818.8 for an average course of study) for EU students currently enrolled. Fees for non-EU students are $€ 50$ or USD 75/credit, but almost all of them are supported by a range of foundations such as the Spanish Carolina Foundation and the American Ford Foundation. Importantly, the chairperson of the MER is authorized by the coordinating university to manage the program's budget.

\section{Organization of the MER}

\section{European Higher Education}

The MER and other master studies were pioneered in Spain as part of the 1999 Bologna Declaration (European Union 1999, Kirkwood-Tucker 2004, Reichert and Tauch 2004) and the European Credit Transfer System (ECTS) (Larsen 2000). The Bologna Declaration aims to improve higher education in EU countries by fostering mobility of both students and lecturers, transparency, and if not consistency at least comparability among institutions of higher education. In practice, this system implies a profound transformation of the previous Spanish way of teaching. Rather than focusing on the time devoted by a lecturer to teach, the new process focuses on the time devoted by the student to acquire skills and learning. Thus our traditional "lecturer standing at the blackboard" model has been replaced by a lecturer whose chief responsibility is to guide the learning process. Consequently, learning based upon individual or small group projects has increased at the expense of student work in classrooms and labs and on field trips. In this type of experimental study, one credit is equivalent to 25-30 hours of a student's time.

The adjustment to this new approach to teaching has been one of the main challenges of the MER. Both lecturers and students have had to move from an active-passive unidirectional model, to a more interactive process in which students, in particular, must take more responsibility. This new approach has led to a rapid evolution of the teaching methodology. For instance, lecturers have reduced by quite a lot the details taught in class but have increased the amount and quality of readings. Similarly, it has affected the organization of classes, such as the teaching sequence of the different subjects. As these changes have been implemented, the student evaluations of the MER have improved steadily. Another 
indicator of improvement is the overall increasingly favorable opinion of the lecturers as regards their subject performance and the opinion of the MER board of directors with respect to the overall master's program performance.

\section{Staff and Facilities}

At present, the MER involves 19 lecturers who are faculty of the four participating universities. The typical major lecturer coordinates one subject, but some of them coordinate two or three. Besides the major lecturers, others from the participating universities, other universities, research institutions, government agencies, companies, and NGOs are often invited to lecture, adding up to literally hundreds of lecturers in the program.

The MER's board of directors includes one major lecturer from each of the four universities, one of whom is the chairperson, a position that will rotate among the members, plus a student coordinator. Additionally, one of the board members acts as the practicum coordinator. We have hired an administrative assistant to assist the board, lecturers, and students in multiple ways (for example, student advisory and administrative work). The administrative and lab staff of the participating departments also provide support to students and lecturers.

The students have to commute among the four campuses to complete all of their classes, though on a given day they attend classes in just one campus. Distance between the two most distant campuses is ca. $50 \mathrm{~km}$. Public transportation, particularly train and underground, is quite good. The inconvenience of commuting for the students is balanced by the advantages of having access to a number of campuses and their facilities, particularly labs. Officially, there is not a departmental home where the students can gather together informally, but in practice they meet in a number of places-particularly at the University of Alcalá, the current chairperson's home institution.

\section{Content and Credits}

The MER consists of 90 credits that are offered in three consecutive four-month terms. Sixty credits pertain to subjects that are taught during the two terms of the first academic year, of which 30 are obligatory and 30 are optional (Table 1). The optional credits allow the student to choose among three specialties: restoration of terrestrial ecosystems, restoration of aquatic ecosystems, and land reclamation.

The practicum and the final report (the MSc thesis) comprise 20 and 10 credits, respectively. These 30 credits are accomplished during the third term and can take place in a 
range of institutions, including research center, university, private or public company, or NGO (www2.uah.es/master_rest_eco/instituciones.html). The students are guided by two advisors, a faculty of the MER program and an advisor based at the practicum host institution. To date, we have collaborated with more than 40 institutions that offer practicum opportunities and have signed collaboration agreements with most of them. These institutions are mostly based in Spain. Students from outside the country are advised to accomplish their practicum in their home country. Eleven students have found practicum opportunities in other countries, including the United Kingdom, the Netherlands, Australia, South Africa, and Chile.

Regulations on postgraduate programs changed at the end of the MER's second year, creating an opportunity to change the contents of our program. We implemented a new "Professional Resources" subject, which includes training on e-libraries, AutoCAD software, oral and written communication, entrepreneurship, and science communication.

Communication skills are a serious handicap in the Spanish education system, especially in science and engineering. One student entrepreneur graduated and is now successfully running her own company, which now offers practicum opportunities to the MER. To further motivate current students to imitate this experience, we decided to include entrepreneur training in this subject.

Other significant changes include changing "Geographic Information Systems” from an obligatory subject to an optional one because of the great range of GIS experience among the students. Owing to the new academic requirements, we also split the former 30-credit practicum into two subjects, namely practicum and "Master Final Report."

\section{The Student Body}

The MER is receiving more applications each year. For 30 offered places, we received 82, 111, 125, and 133 regular applications from Spanish and other European students in each of the first four years (2006 to 2009) of the program, plus 556, 606, and 691 applications from Latin American students from the second year onward. This was made possible thanks to generous support (seven scholarships per academic year) supplied by the Carolina Foundation (www.fundacioncarolina.es/es-

ES/becas/presentacion/Paginas/presentacion.aspx), a Spanish governmental foundation for promoting university education for students from Latin American countries. This high demand allows the board of directors to be very selective. We choose students on the basis of both their previous academic performance and activities that strengthen university teams and 
international networks. For example, if an MER applicant has an agreement to work with an MER lecturer on a body of research related to the MER program, that student would be favored in the selection process. Similarly, students coadvised by two lecturers who are faculty of different universities participating in the program would be given preference.

To date, 130 students from 16 European and Latin American countries have enrolled in the program, with a minimum of seven countries represented each year. Not surprisingly, the majority of students (71\%) come from Spain. The academic background of most students (> 80\%) is mainly in biology, environmental sciences, and forest sciences. Less common backgrounds are agronomy, geology, geography, and political science. Most European students had recently completed their undergraduate degrees when they enrolled in the MER. However, most of our Latin American students have had previous professional experience because the Carolina Foundation scholarship requirements favor students with real-world work experience.

The high demand for our program is a quality indicator and fits with one of the main aims of the current European Higher Education Program, which seeks to attract students and, insofar as possible, researchers and lecturers from all over the world. We consider the multidisciplinary and multinational origins of the student body to be a major strength of the MER. However, the variable backgrounds of our students can make it difficult to teach certain subjects.

Students have showed a high commitment to the MER, reflected by the noticeable amount of time devoted to classes, achieving good marks, the quality of group work and associated presentations, the proactive arrangement of practicum opportunities, and the quality of their final report. The frequent requests from students for advice on their "professional life" also indicate commitment. At the same time, students have high expectations about "their" MER and are very demanding regarding the quality of teaching and interaction with the teachers. Student concerns are collectively transmitted to the MER student coordinator once per term, and the report is then sent to the board of directors, who must address any concern.

\section{Postgraduation Outcomes}

As of October 2009, we can report on the career development of 57 students from the first two cohorts; the third has not yet finished. No fewer than $79 \%$ of graduates achieved a favorable employment scenario (Table 2), despite job hunting in a period of worldwide economic recession. A substantial part of this very positive result has to do with the broad 
training of the MER. So far, more than 40 institutions have effectively collaborated with the program as practicum host institutions. A number of those institutions have hired the hosted students after completion of the MSc. Thirteen students are currently working on their PhDs (a minimum of a 60-credit master's degree is now required to enroll in a $\mathrm{PhD}$ program in any certified university in the European Union). Additionally, the multidisciplinary character of the lecturers and participating institutions facilitates a range of career development paths.

The career potential for new MER graduates is impeded somewhat by the fact that professional associations "protect" their associates (that is, closed professional guilds). For example, several MER graduates have proven themselves to be able to write, direct, and supervise mining reclamation and civil work projects according to best international standards in the field. However, the professional organizations of the Spanish mining engineers and civil engineers are very reluctant to admit other professionals in this area. To protect themselves, these professional associations exclude other professionals such as the MER graduates. Fortunately, some engineers recognize the skills of MER graduates and a few have sought our collaboration. The MER cannot—as yet!-influence either the laws or the administrative situation in any country, even Spain, but instead concentrates on providing the best possible education for our students. We strongly believe that these students will influence the overall situation of ecological restoration within society in the near future.

\section{Concluding Remarks}

Students who enroll in the MER program gain a network of relationships with other students and well-reputed lecturers. They also acquire skills and knowledge and are exposed to many different points of view and approaches regarding ecological restoration issues. They obtain direct professional experience at collaborating institutions, an official degree recognized throughout Europe, the chance to fulfill the requirements that will enable them to apply for a $\mathrm{PhD}$ degree program, and, finally, a high probability of quickly finding an appropriate job after finishing their studies.

The major strengths of the MER are the multidisciplinary nature of the program, expertise and professional reputation of involved lecturers, high number of involved lecturers and institutions in the program, management autonomy of the program budget, diverse background and provenance countries of the students, high demand for enrollment, and a high rate of postgraduate employment. Weaknesses include challenges in teaching students with different backgrounds and that some professional organizations are engaging in job protection politics, creating employment obstacles for graduates. The main challenge of the 
board of directors and lecturers is to motivate the students to be proactive and to promote new ideas and approaches in order to improve the MER year after year. We operate on the principle that it is the students who "make" their MER, and we encourage them to speak up, propose ideas, and criticize freely.

The MER helps to achieve the mission of the Society for Ecological Restoration International, which, among other things, is now debating whether to develop a certification program for restoration practitioners. We think that the MER would fulfill high standards of training in this area. The program teaches students to view ecological restoration as an indispensable component and, in some cases, a driving engine of sustainable development, which is the slogan of the upcoming Seventh European Conference on Ecological Restoration, to be held in Avignon, France, in August 2010 (www.ser.org/europe/).

\section{Acknowledgments}

We are indebted to all the people who have made and make the MER possible, particularly M. Heykoop and P. Moscoso (Vice-chancellors); M.L. Díaz, C. de la Peña and M. C. Marina (administrators); J. Díaz, A. Guerrero and L. Pérez-Camacho (assistance staff); S. Ruiz and J.I. Gómez (hired ad hoc assistants of the MER); and S. de Alba, R. Elena, R. Espejo, D.

Gómez, A. López, J.M. Iriondo, F. Maestre, J. de Pedraza, S. Rebollo, C. Romero, A. Rubio, R. Serrada, M.J. Salado, J. Salas and R. Viejo (major lecturers). We are indebted as well to all involved institutions (list available at www2.uah.es/master_rest_eco/instituciones.html). Thanks to J. Aronson for encouraging us to write this manuscript and for commenting on previous versions, and to Chris Reyes and Mrill Ingram for valuable comments and editing. The MER is partially a product of the Remedinal Research Network (S-0505/AMB/0335 and S2009AMB-1783). Projects CGL2007-60533/BOS (CICYT, Ministry of Education and Science, Spain), Reforlan (EU INCO Contract CT2006-032132), and many others use the MER for dissemination of research activities.

\section{References}

European Union. 1999. The Bologna Declaration of 19 June 1999: Joint declaration of the European Ministers of Education. www.bologna-bergen2005.no/Docs/00Main_doc/990719BOLOGNA_DECLARATION.PDF

Guimerà, R., B. Uzzi, J. Spiro and L.A. Nunes Amaral. 2005. Team assembly mechanisms determine collaboration network structure and team performance. Science 308:696703.

Kirkwood-Tucker, T.F. 2004. Towards a European model of higher education: Problems, processes, and promises. European Education 36(3):51-69. 
Larsen, B.S. 2000. The European credit transfer system (ECTS): Introduction and practical experience at the Technical University of Denmark. Water Science \& Technology 41:61-66.

Reichert, S. and C. Tauch. 2004. Bologna four years later. European Education 36(3):36-50.

José M. Rey Benayas is professor at the University of Alcalá and currently leads the Spanish Master in Ecosystem Restoration and the PhD Program in Ecology, Conservation and Restoration of Ecosystems. His research is focused on the restoration of biodiversity and ecosystem services in agricultural landscapes. He can be reached at josem.rey@uah.es, Dpto de Ecología, Universidad de Alcalá, E-28871 Alcalá de Henares, Spain.

Adrián Escudero, Dpto de Biología y Geología, Universidad Rey Juan Carlos, C/ Tulipán s/n, E_28993 Móstoles, Spain

José F. Martín Duque, Dpto de Geodinámica, Facultad de Geología, Universidad Complutense de Madrid, E-28040 Madrid, Spain

José M. Nicolau, Escuela Politécnica Superior, Carretera Cuarte, s/n, E-22071 Huesca, Spain

Pedro Villar-Salvador, Dpto de Ecología, Universidad de Alcalá, E-28871 Alcalá de Henares, Spain

Diego García de Jalón, Laboratorio de Zoología, Universidad Politécnica de Madrid, ETSI Montes, E-28040 Madrid, Spain

Luis Balaguer, Dpto de Biología Vegetal I, Facultad de Biología, Universidad Complutense de Madrid, E-28040 Madrid, Spain 
Table 1. Organization of the Master in Ecosystem Restoration by subject. An asterisk indicates that the subject was changed in the fourth year of the program, based on our experience during the first three years (see text for further explanation). Subjects in shaded rows are obligatory.

\begin{tabular}{lccl}
\hline Subject & Term & Credits & Specialties \\
\hline Environmental degradation and ecosystem restoration* & 1 & 6 & All \\
Conservation biology & 1 & 5 & All \\
Geology, geomorphology, and soils & 1 & 5 & All \\
Professional resources* & 1 & 5 & All \\
Territory and socio-economy & 1 & 5 & All \\
Geographic Information Systems* & 1 & 4 & All \\
Projects* & 2 & 5 & All \\
Restoration of inland aquatic ecosystems* & 2 & 6 & Aquatic systems \\
Revegetation & 2 & 6 & All \\
Forest restoration & 2 & 5 & Terrestrial systems \\
Restoration of sites affected by civil engineering & 2 & 5 & Land reclamation, aquatic systems \\
Restoration in rural and suburban ecosystems & 2 & 5 & All \\
Design and construction of topography & 2 & 4 & Land reclamation \\
Restoration of arid ecosystems & 2 & 4 & Terrestrial systems \\
Restoration of sites affected by mineral extraction & 2 & 4 & Land reclamation, aquatic systems \\
Restoration of wildlife habitat & 2 & 4 & All \\
Restoration of coast and marine ecosystems & 2 & 3 & Aquatic systems \\
Restoration of degraded soils & 2 & 3 & Land reclamation, terrestrial systems \\
Restoration of polluted soils & 2 & 3 & Land reclamation \\
Restoration of populations & 2 & 3 & All \\
Practicum* & 3 & 20 & All \\
Master Final Report* & 3 & 10 & All \\
\hline
\end{tabular}


Table 2. Career development of graduates of the Master in Ecosystem Restoration Program (first two years, 57 enrolled students).

\begin{tabular}{lccc}
\hline Type of institution/situation & Number & & $\%$ \\
\cline { 1 - 2 } Public organizations, including universities and research centers & 12 & 21.1 \\
PhD students & 10 & 17.5 \\
Private companies & 10 & 17.5 \\
Associations, foundations and NGOs (not-for-profits) & 7 & 12.3 \\
Public administration & 2 & 3.5 \\
Independent entrepreneurs & 1 & 1.8 \\
Unemployed & 3 & 5.3 \\
Other situations & 4 & 7.0 \\
Lack of news & 8 & 14.0 \\
\hline
\end{tabular}

